\title{
Research on Issues and Countermeasures of Urban-rural Endowment Insurance Integration
}

\author{
Jie Zhou ${ }^{1}$, Xiaolan Zhang ${ }^{1}$ \\ ${ }^{1}$ Shijiazhuang Staff University, Shijiazhuang, 050000, China
}

Keywords: Urban-rural integration, Endowment insurance, Pattern exploration

\begin{abstract}
To narrow urban and rural development gaps in recent years, realization of urban-rural endowment insurance integration is an important content of the reform of social security system in China. In recent years, China has continuously completed endowment insurance system, and expanded coverage groups of social insurance. Almost all urban employees were covered in the range of endowment insurance. Due to restraint from city-countryside dualization structure in China, urban and rural economic development is imbalanced. Rural endowment insurance system is different from urban endowment insurance system in terms of payment and delivery, which influences free circulation of labor to some extent. In this paper, the author centered on the theme of urban-rural endowment insurance integration, and proposed countermeasures for existing issues from the angles of payment standard, completion of pension insurance fund management and supervision enhancement based on current implementation conditions of endowment insurance system.
\end{abstract}

\section{Necessity of Urban-rural Endowment Insurance Integration}

Balance of urban and rural endowment insurance is performed under the background of China's dual economic structure. Viewed from the angle of social equity, development of rural endowment insurance is of great significance for balance of urban and rural endowment insurance. However, the theory of welfare economics gives supports to balance of urban and rural endowment insurance from the angle of social welfare. Social endowment insurance has the nature of public products. Public services provided by the government to its residents should be equalized as much as possible. However, endowment insurance works for rural and urban residents are separately managed. With increasingly frequent labor mobility nowadays, urban and rural dual endowment insurance policies bring forth difficulties to guarantee of laborer rights and interests, restraining stable development of social economy. Rational configuration of labor resources can be realized only by balanced endowment insurance development of urban and rural residents and promotion of urban-rural endowment insurance integration, so as to coordinate urban and rural economies, make urban and rural residents enjoy equal rights and interests, and achieve the goal of constructing well-to-do society.

\section{Issues Existing in Current Endowment Insurance System in China}

\section{Not high policy execution efficiency}

In 2011, China's endowment insurance system realized overall coverage. In actual operation, however, some residents are still not covered in the endowment insurance system. This issue is more obvious in rural regions. Only when various regulations are guaranteed from formulation to implementation, China's basic endowment insurance system can really become a people-benefit project. This is also a key point to be further improved in the process of governmental work. In some regions, it is sufficient for publicity of relevant endowment insurance systems by governmental departments, resulting in local residents' inadequate understanding of this system. More seriously, they even misunderstood this system, bringing forth huge difficulties for endowment insurance integration. 


\section{Not obvious function of redistribution}

At present, it can be known that income of urban residents is approximately 5-6 times of that of rural residents in China according to subsidies to urban residents in social security and education and investment to peasants' means of production. At the same time, realization modes of our endowment insurance system are basically correlated with personal account. The final insured amount obtained is in positive correlation with personal costs initially paid, namely the system of "more payment more gain”. Therefore, this system is unfavorable for low-income groups in rural areas. It also goes against the goal of endowment insurance: guarantee people's life, and adjust income redistribution.

\section{Unbalanced development of urban-rural endowment insurance systems}

Social insurance is a core part of social security system in China. However, endowment insurance plays a key role in guaranteeing the life of urban and rural residents. To complete multi-layer endowment insurance system, we should enhance management of basic endowment insurance, and complete policies related to enterprise annuity and personal saving deposited insurance beneficial for urban and rural residents. For imbalanced development of China's endowment insurance system, the State Council proposed a measure: based on distribution of endowment insurance depending on personal payment, the state will give a series of subsidies, so as to really realize endowment insurance benefiting the people. Besides, we should give full play to advantages of enterprise annuity and commercial annuity in realization of urban-rural endowment insurance integration, and enhance value preserve and increase capacity of insurance fund, so as to make up insufficiencies of basic endowment insurance system and make the whole endowment insurance system more coordinated.

\section{Incomplete policies and regulations}

At present, relevant laws and regulations of endowment insurance are still incomplete. It is difficult to link up endowment insurance of different groups with different identities. The government, as main planner and executor of endowment insurance system, should positively develop coordination, especially for the departments related to endowment insurance system. The government should enhance management, making such departments help urban-rural endowment insurance systems to be performed in a smoother way. In terms of policy formation, the government should complete subject systems, and make adjustment to the polices for relevant marginal areas, such as community endowment and community health care policies closely related to senior citizens. Besides, low guarantees policies should also conform to people's increasingly growing living needs, giving basic life guarantees to people at the bottom of society.

\section{Analysis on Factors Restraining Urban-rural Endowment Insurance Integration}

\section{Economic level decides difficult promotion of single standard.}

No matter divided from region or urban and rural areas, China's economic development is seriously imbalanced. This situation decides that our basic pension insurance system should make innovations and get rid of single policy. For different regions, we should use for reference local economic development conditions and residents' living standards, and adopt different implementation methods. For rural areas, we should enhance the degree of policy implementation, consider formulating more favorable endowment insurance system for peasants, and improve the issue of the old people's life excluded from enough guarantee due to low payment. In recent years, endowment insurance system has already obtained remarkable achievements in the promotion process. At the same time, many issues are also revealed. For instance, some local governmental management personnel are influenced by the thought of quick success. To pursue for short-term economic benefits, they excessively depend on guarantees offered to the people by land, and overlooked the function of endowment insurance system, resulting in low effect of rural endowment insurance. This goes against the development goal of urban-rural integration, bringing some risks to both life and social stability of peasants.

\section{Existence of barriers in household registration system}

In recent years, the household registration system already shows its defects, blocking the development of market economy. For this issue, many regions attempted to reform. Generally, it 
failed to realize remarkable overall effect. In most Chinese regions, both social security policy and economic subsidy are based on household registration system. For more and more floating population, it is difficult for them to enjoy such treatment. During their works in cities, peasants cannot enjoy existing urban endowment insurance system. Therefore, they will not give up their relations with land. These current conditions are unmatched with the initial functions of household registration system. This is also a basic reason for difficult implementation of basic endowment systems in rural and urban areas. It also seriously hinders the development of urban and rural integration.

\section{Difference in local financial pressure}

For implementation of endowment insurance system, various regions made relevant explorations according to local conditions. Among these regions, Shanghai obtained a series of theoretical achievements for integration of basic endowment insurance, and formed a "Shanghai pattern" with unique features. In Shanghai, relevant systems were made for different groups of people. In the initial stage of trial implementation of basic pension insurance system, Shanghai solved the issue of big difference in guarantee level between different groups of people. In Jiangsu and Guangzhou, social insurance departments also provided relevant government subsidies to different groups, and implemented policies for integration of urban and rural endowment insurance according to local conditions. No matter for system completion or direct subsidies, however, this brings forth huge financial pressure to the government. Different financial supports lead to different development levels of urban and rural endowment insurance. Moreover, it is difficult for link-up due to different payment standards for endowment insurance.

\section{Implement Approach for Pattern of Urban-rural Endowment Insurance Integration}

\section{Design multi-layer endowment insurance payment standards for urban and rural areas,} select by urban and rural residents according to their wills, and encourage the mode of "more payment more gain"

To expand the coverage of endowment insurance and realize urban and rural integration, we should make different endowment insurance payment systems with local features according to different groups of residents. Moreover, we should also correlate payment with personal income, and implement different payment systems for residents in different classes of income. Under the same payment system, both urban and rural residents can be guaranteed by endowment insurance system. Based on national standards for payment of endowment insurance, various regions can make it more detailed for these standards according to local conditions. Moreover, grades of endowment insurance for urban and rural residents should be taken into consideration, so as to realize voluntary payment based on multi-grade selection and the policy of "more payment more gain". Moreover, local governments should also establish reasonable payment accounts, enabling the insured to inquire their payment conditions at any time.

At the same time, the government should encourage and develop multi-layer social endowment insurance systems, persist in the policy of "basic endowment insurance aided by family supporting and supplementary guarantee”, positively develop community endowment service undertakings, standardize endowment service institutions, and promote industrialization and specialization of endowment service undertakings. On the one hand, the government should remit differences caused by financial pressure. On the other hand, the government should meet diversified endowment needs of senior citizens.

Improve the government's public management level. And promote networking management of endowment insurance information

The system of endowment insurance integration is implemented in China. The biggest advantage of this system is that it combines distribution of old age security pension with economic level and living standards of different groups of people and takes payment capacity of these people into full account. Through "social security card" and other specific information modes, this system makes all people enjoy social insurance, solving the endowment issue of some professionals. For floating 
population, this is a more specific and more suitable pattern of old-age security. At the same time, this management mode also shows the government's high-efficiency management level.

Relevant local departments are encouraged to establish supervisory bodies related to social insurance and complete social public service systems. The system of social security card is an effective means of endowment insurance informatization. Various local governments also positively established special management departments, took unified management measures under combination of multiple channels, improved working efficiency of endowment insurance, and completed basic information of endowment insurance database. At the same time, local governments also vigorously promoted e-government affairs, allowed new office system to benefit urban and rural residents, and enabled them to transact insurance procedures through Internet banking and relevant endowment insurance websites, making it more transparent for information and clearer for system. Administrative staff can promptly communicate with the masses, which is beneficial for works of relevant supervision departments. At the same time, it can also reduce the occurrence of fund embezzling, corruption and other phenomena and enhance guarantees for people's interests.

Complete pension fund management mechanism, and enhance financial investment to economically underdeveloped areas

According to relevant statistics, by the end of 2013, the society accumulatively invested RMB 3,290 billion into endowment insurance industry. Total balance of endowment insurance fund was RMB 3,127.5 billion. In 2011, the central government of China accumulatively invested RMB 39.9 billion into the field of basic endowment insurance for urban and rural residents. Various local governments accumulatively invested RMB 47.9 billion. It can be found from above data that Chinese government invested much into endowment insurance. However, it is difficult to realize maintenance of value, making actual endowment insurance fail to meet people's needs.

At first, Chinese government should establish endowment insurance fund value maintenance and appreciation system, vitalize all funds raised, realize appreciation and value maintenance of this category of funds, and make endowment insurance funds to provide better interests to urban and rural residents. Moreover, Chinese government should also establish and complete basic fund management system, enhance coordination between pension insurance fund management center and financial, tax administration, auditing and other departments, combine frequent supervision and inspection with special inspection, guarantee transparency of fund operation, give play to the function of external supervision, and ensure standard and orderly operation of funds.

Secondly, Chinese government should implement nationwide planning system of endowment insurance fund. At present, provincial-level planning system already solved great payment pressure. With further implementation of urban and rural endowment insurance integration, however, it becomes bigger and bigger for planning funds. To realize effective value maintenance of this category of funds to a large extent, Chinese government should enhance nationwide planning for endowment insurance funds.

Complete laws and regulations, establish endowment insurance cohesive mechanism of urban employees and urban-rural residents, and break barriers of urban and rural systems

To realize urban and rural endowment insurance integration, Chinese government must establish an effective cohesive mechanism of urban and rural social insurance. At first, Chinese government should establish relevant laws and regulations to guarantee the cohesive mechanism, and make detailed settings for cohesive contents in the system framework, for instance, establishment of urban and rural social security conversion system and conversion of relevant payment rights and interests. Such cohesive mechanism makes it convenient for insurance variations of more insured people. Second, the cohesive mechanism should be established in a higher level. Provincial-level cohesion is beneficial for planning on social security fund and reduction to costs for planning. Moreover, implementation of follow-up goals lays a foundation for planning. Third, Chinese government should implement informationalized cohesive mode. Establishment of information database makes each citizen have their own social security accounts, reducing cohesive difficulty. Moreover, it is more beneficial for future implementation of urban and rural insurance integration. Fourth, Chinese government should gradually eliminate barriers for labor mobility, deepen the reform of household 
registration system, implement unified household registration management system, adjust residence migration policy, loosen urban settlement restraints under a proper plan, and make all social members share social development achievements.

\section{Conclusion}

To complete social security system, make urban and rural residents enjoy equal rights and interests, and complete the goal of overall construction of well-to-do society, China must realize integration of urban and rural endowment insurance. Centering on current conditions of basic endowment insurance system in China, the author explored for the issues existing in China's endowment insurance system and endowment insurance promotion mode. At the same time, the author also listed successful experiences of some regions in development of endowment insurance, and further proposed relevant solutions, providing rich theoretical contributions to the research on urban and rural endowment insurance integration mode in China.

\section{References}

[1] Li Wei, Research on Planning as a Whole Basic Endowment Insurance System of Urban and Rural Residents - With Zhengzhou City of Henan Province as as Example, Jiangsu Agricultural Sciences, 2012, (05);

[2] Chen Tianxiang, “Gradual Unification” of Urban-Rural Social Secuity Intergration Pattern With Dongguan City as as Example, Journal of Central China Normal University(Humanities and Social Sciences), 2010, (01);

[3] Li Yanjie, Trend of Wide Coverage of Chinese Social Security and Its Legal Significance - With Investigation of Basic Endowment Insurance as an Example, Journal of China Institute of Industrial Relations, 2012, (06);

[4] Li Weixin and Wang Ruyin, Preliminary Exploration for Construction of New Rural Endowment Insurance System in Heilongjiang Province, Economig Rfsearch Cuide, 2010, (29);

[5] Liu Fu, Wang Shaochun and Li Renrong, Starting Point of Urban and Rural Planning Social Security Development - New Rural Endownment Insurance, Rural Economy, 2009, (10)

[6] Van Ginneken,W.Extending social security:Policies for developing countries. ESS Paper No.13.2003. 